\title{
Formación de maestros(as) en América Latina Encuentro de rectores(as) y directivos(as) académicos(as) Octubre 5 y 6 de 2015 Bogotá - Colombia
}

Por primera vez me parece buena una cadena para atar, dentro de un cerco mismo, a todos los pueblos de mi América.

José Martí

\section{Presentación}

Los procesos de formación pedagógica implican el reconocimiento de principios éticos, una apuesta política, una puesta en escena estética y un proceso cognitivo, donde se pone de manifiesto la responsabilidad nuestra como maestros(as), directivos(as) y rectores(as) en los diálogos y en el compromiso con un "otro" que es radicalmente diferente. Por ello, todo proceso formativo implica una relación de alteridad y responsabilidad, una relación con el otro donde el extraño se convierte en cómplice.

Recientes propuestas y políticas educativas de organismos internacionales y autoridades nacionales en América Latina han concentrado su atención en los(as) maestros(as) como "factor" decisivo en el desempeño de los(as) estudiantes en las pruebas estandarizadas. Una multitud de estudios, particularmente procedentes de investigaciones originadas en el mundo anglosajón, se han ocupado de caracterizar ese importante "factor" para diseñar estrategias que permitan cualificar la actividad docente, mejorar las prácticas en aula, los aprendizajes y los resultados de los estudiantes en las pruebas.

En el marco de esta tendencia, con perspectiva analítica, crítica y propositiva, el objetivo de nuestro encuentro es preguntarnos por las discusiones y acciones que las universidades pedagógicas y facultades de educación latinoamericanas promovemos al respecto; por lo que hacemos, dejamos de hacer y podemos hacer frente a la formación de maestros(as). Por ello la necesidad de realizar una convocatoria que permita un reencuentro entre nuestras instituciones, un escenario de reconocimiento y aproximación en la perspectiva de favorecer la promoción y el diseño de acciones conjuntas para repensar la formación de maestros(as) en América Latina.

En consonancia con lo anterior, este encuentro de rectores(as) y directivos(as) académicos comprometidos con la formación docente en Latinoamérica se propone como escenario propicio y necesario para el diálogo de saberes en torno a la formación de maestros(as); diálogo que posibilitará reconocer las perspectivas y problematizaciones que se debaten hoy en América 


\section{Buncites}

Latina situadas en las siguientes preguntas: ¿En qué escenarios y políticas se mueve hoy la formación de maestros(as) en nuestros países? ¿Cuál es el saber teórico, epistémico y contextual que necesitamos como instituciones formadoras de maestros(as) para una sociedad justa y en paz? ¿Qué propuestas políticas y pedagógicas vamos a construir en el escenario del evento con respecto a: i) sistema de formación de maestros, ii) lineamientos curriculares para los programas de formación y iii) la evaluación de maestros(as) como estrategia de formación continuada?

Pero, además, será el momento oportuno para diseñar en conjunto estrategias de cooperación e intercambio académico, de internacionalización de nuestros currículos, movilidad estudiantil y docente, investigación compartida, publicaciones conjuntas, doble titulación, entre otros aspectos que pueden cualificar el desarrollo de nuestros programas para la formación de maestros(as).

\section{Propósitos}

Invitar a la reflexión sobre la formación de maestros(as) en el escenario de un diálogo latinoamericano con rectores(as), directivos(as) y profesores(as) de universidades pedagógicas e institutos de formación de maestros en Latinoamérica.

Analizar los contextos de actuación en los que se sitúa la formación de maestros(as), particularmente inscritos en dinámicas de exclusión, desigualdad, violencia política y social, procesos de negociaciones de paz.

Reflexionar sobre las trayectorias en la formación de maestros(as), deseables y necesarias, que contribuyan a su dignificación y valoración cultural y pedagógica.

Construir una agenda interinstitucional que posibilite la cooperación académica.

Este evento es convocado por los rectores Tenoch Esaú Cedillo, de la Universidad Pedagógica Nacional de México, y Adolfo León Atehortúa Cruz, de la Universidad Pedagógica Nacional de Colombia.

\section{Inscripciones}

Entrada libre a los eventos públicos con previa inscripción desde el 16 de septiembre hasta el 3 de octubre de 2015 en www.maestrosamericalatina.pedagogica.edu.co 


\section{Programación}

\section{Lunes 5 de octubre}

Auditorio Alfonso López Pumarejo

Carrera 45 n. ${ }^{\circ}$ 25-85, Edificio Uriel Gutiérrez, piso 1 Universidad Nacional de Colombia

\section{Actividades}

Evento público

Carrera 45 n. ${ }^{\circ}$ 26-85 8:00 a. m. a 1:00 p. m.

Auditorio Alfonso López Pumarejo (Edificio Uriel

Gutiérrez, piso 1)

Universidad Nacional de Colombia Bogotá, Colombia

\section{Mayores informes:}

Odemaris Vera Hernández

(57-1) 5941894 ext. 109

overa@pedagogica.edu.co

ori@pedagogica.edu.co

maestrosamericalatina.pedagogica.edu.co

Octubre 5 y 6 de 2015

Bogotá, Colombia

Evento público

8:00 a.m.

8:30 a.m.

Apertura:

Acto inaugural del evento 9:00 a.m.

\section{Conferencia:}

Formación de maestros(as) en América

Latina: problematizaciones y perspectivas
Inscripciones y entrega de escarapelas

Adolfo León Atehortúa Cruz, Rector de la Universidad Pedagógica Nacional, Colombia.

Tecnoch Esaú Cedillo, Rector de la Univer-

sidad Pedagógica Nacional, México.

Alejandra Elena Birgin, Magistra en Educación y Sociedad. Universidad de Buenos Aires, Argentina.

Etelvina Sandoval Flores, Doctora en Pedagogía. Universidad Pedagógica Nacional, México.

Julio Sánchez Maríñez, Rector del Instituto Superior de Formación Docente Salomé Ureña, República Dominicana.

Adrián Cannellotto, Rector de la Universidad Pedagógica Provincial (UNIPE), Argentina.

Moderador:

Leonardo Fabio Martínez, Doctor en Educación para la Enseñanza de la Ciencias y la Matemática. Universidad Pedagógica Nacional, Colombia.

\section{Conferencia}

Políticas de formación de maestros(as)

11:30 a. m.

Comentaristas: 